\title{
Article \\ Power Generation Control of Renewable Energy Based Hybrid Deregulated Power System
}

\author{
Zahid Farooq ${ }^{1}\left(\mathbb{D}\right.$, Asadur Rahman ${ }^{1, * \mathbb{C}}$, S. M. Suhail Hussain ${ }^{2, t, \mathbb{C}}$ and Taha Selim Ustun ${ }^{2, *(\mathbb{D})}$ \\ 1 Electrical Engineering Department, National Institute of Technology Srinagar, Srinagar 190006, \\ Jammu and Kashmir, India; erzahidbhat@gmail.com \\ 2 Fukushima Renewable Energy Institute, National Institute of Advanced Science and Technology (AIST), \\ Koriyama 963-0215, Japan; suhail@ieee.org \\ * Correspondence: asadur2003@yahoo.co.in (A.R.); selim.ustun@aist.go.jp (T.S.U.) \\ + Current address: Department of Computer Science, National University of Singapore (NUS), 21 Lower Kent \\ Ridge Rd., Singapore 119077, Singapore.
}

\begin{abstract}
This work presents the power generation control of a two-area, hybrid, deregulated power system integrated with renewable energy sources (RES). The incorporation of appropriate system non-linearities and RES into the power system makes it complex, but more practical. The hybrid deregulated power system with RES is a complex nonlinear system that regularly exposes the major issue of system dynamic control due to insufficient damping under varying loading circumstances. The generation-demand equilibrium point of the power system varies following a contingency; hence, it becomes difficult to maintain the appropriate equilibrium point via traditional control approaches. To solve this problem, novel control approaches, along with rapid-acting energy storage devices (ESD), are immediate need for advanced power systems. As a result, various secondary controllers are inspected for improvements in system dynamics. A performance comparison infers the cascaded ID-PD controller as the optimum one. The secondary controller gains are successfully optimized by the powerful satin bowerbird optimization (SBO) technique. Additionally, the impact of a superconducting-magnetic-energy-storage (SMES) device in system dynamics and control of developed power system is analyzed in this study. A sensitivity evaluation (SE) infers that SBO-optimized cascaded ID-PD controller gains are strong enough for alterations in load perturbations, system loading, inertial constant $(\mathrm{H})$, solar irradiance and the DISCO involvement matrix (DIM).
\end{abstract}

Citation: Farooq, Z.; Rahman, A.;
Hussain, S.M.S.; Ustun, T.S. Power Generation Control of Renewable Energy Based Hybrid Deregulated Power System. Energies 2022, 15, 517. https://doi.org/10.3390/en15020517

Keywords: load frequency control (LFC); renewable energy sources (RES); deregulated hybrid power system; energy storage device (ESD); cascaded controller

Academic Editor: Ahmed Abu-Siada

Received: 8 November 2021

Accepted: 6 January 2022

Published: 12 January 2022

Publisher's Note: MDPI stays neutral with regard to jurisdictional claims in published maps and institutional affiliations.

Copyright: (C) 2022 by the authors Licensee MDPI, Basel, Switzerland. This article is an open access article distributed under the terms and conditions of the Creative Commons Attribution (CC BY) license (https:// creativecommons.org/licenses/by/ $4.0 /)$.

\section{Introduction}

Ensuring the integrity, consistency, and reliability of the power system is critical for obtaining a continuous and efficient power supply [1]. The overall quality of the power system relies heavily on the frequency stability. Load frequency control (LFC) plays a vital role in keeping the system dynamics at their scheduled values [2,3]. Therefore, LFC is essential in generating the quality power and maintaining frequency at their supposed values for a stable operation.

The power sector is being deregulated all over the world from a vertical integrated market into a variety of companies in each continuum of the power system. Several companies in the deregulated power market are at liberty for power transactions in the same or a different control area. LFC becomes extremely challenging following the deregulation of the power system, as it is the vital auxiliary service in power system stability [4].

\subsection{Related Literature and Limitations}

Hydro and thermal units are the primary sources of electricity in the medieval era. The literature survey $[5,6]$ mainly reports the LFC problem incorporated with hydro and thermal units as major power-producing units. However, the essential need for the present 
power system is the incorporation of applicable system non-linearities. Different system non-linearities, in the form of a generation-rate-constraint (GRC), governor-dead-band (GDB) and time-delay, were used by several authors $[7,8]$ in the frequency/tie-line power control of a hybrid power system for practical implementations.

As traditional energy sources become limited and depleting, renewable energy sources (RES) are gaining prominence [9]. Renewable sources are ecologically sound, and their efficacy is steadily rising. Solar energy is the most commonly used renewable source in power system studies [10]. The solar-thermal-system (STS) is used by several authors [11,12] for a system dynamics control of hybrid power systems. STS, in addition to the wind turbine system (WTS), for the system dynamics control of a multi-area power system is reported in [13]. A detailed analysis of renewable sources in smart grids is illustrated in [14]. To integrate RES into the existing grid and avoid power variations, energy storage devices are generally required [15]. Several reports [16,17] have shown the impact of energy storage devices (ESD) in enhancing the system dynamics of a modern power system. The importance of ESDs in a deregulated power system incorporated with a geo-thermal plant is discussed in [18]. The authors in [19] have effectively shown the impact of a super-magnetic energy-storage (SMES) device (RFB) in a practical power system, and the attained results are very encouraging. The aforementioned reports infer that very few authors have shown the effect of SMES on the frequency control of a deregulated power system. Therefore, the authors aim to show the impact of SMES in a deregulated power system with applicable system non-linearities.

Geo-thermal energy (GTE) is another effective and developing renewable source, which is used to generate power all over the globe. Effective frequency control strategies in the presence of GTE are discussed in [20]. The authors in [21] have efficiently discussed the impact of GTE in addition to other renewable sources for the LFC operation of a power system. From the aforementioned literature, a few authors have documented work on the system dynamics' regulation of a multi-area power system including GTE and other renewable sources.

Due to the importance of frequency control as an ancillary service, various research articles have examined its performance in a deregulated power market. The issues related to frequency control in a deregulated power market are elegantly addressed in [22]. The authors in $[23,24]$ have discussed the LFC problem in a deregulated power system with hydro-thermal units. However, the study presented by [25] discussed LFC issues in both a regulated and deregulated power system. The different companies involved in the deregulated power market are free to enter power agreements. To ease the understanding of power agreements between generation companies (GENCOs) and distribution companies (DISCOs), the literature [26] introduced the DISCO involvement matrix (DIM) for a deregulated power system. The authors in [27] effectively utilized the DIM idea in an interconnected thermal power system, where DIM elements are known as agreement participation factors (Apf) [27]. The area-output heavily relies on the area control error (ACE), whereas power generation depends on the area involvement factor [28]. A comprehensive LFC study of a hybrid deregulated power system with non-linearities is discussed in $[29,30]$. The importance of geo-thermal (GT) energy in improving the system dynamics of a deregulated power system is efficiently discussed in [31]. The aforementioned literature [22-31] reflects that limited literature is available on the importance of renewable sources in a deregulated power market. Hence, this calls for a detailed inspection.

The presence of appropriate system non-linearities can lead to a power system with undesired oscillations. Furthermore, the uneven load demand can cause system instability. To evade this situation and handle the growing complexity of a modern power system, a robust secondary controller is essential. In this regard, several secondary controllers have been reported in the literature for the LFC operation of a hybrid power system. A PIDDcontroller-based dynamic frequency regulation of a multi-area power system is discussed in [32]. An advanced controlling approach viz cascaded controllers is used by several studies $[33,34]$ for the improved LFC operation of a hybrid power system. The system uncertainties are effectively handled with cascaded controllers [34]. An informative review 
paper on novel controller strategies in a renewable-sources-based hybrid power system is discussed in [35]. According to the aforementioned literature, cascaded controllers are useful when enhancing the dynamic stability of the power system. However, there is limited research discussing the importance of cascaded controllers in a hybrid deregulated power system. Therefore, the authors are motivated to utilize a cascaded controller in a hybrid deregulated power system .

For the stable and efficient operation of a power system, the controller gains must be set at their optimum values. In this view, meta-heuristic bio-inspired optimization techniques have been very successful in power system studies. A new bio-inspired satin bowerbird optimizer (SBO) technique [36] is available in the literature, which has not yet been applied in power system studies. Therefore, the authors aim to optimize different secondary controller gains using the $\mathrm{SBO}$ technique.

\subsection{Contribution and Objectives}

This study examines a hybrid deregulated power system integrated with renewable energy sources. The vital contributions with respect to this work are mentioned below:

- The cascaded ID-PD controller is applied for system dynamics control of a hybrid deregulated power system.

- The impact of a solar-thermal-system (STS) and geo-thermal (GT) plant on system dynamics.

- The inclusion of an SMES device in addition to RES to regulate the system dynamics.

- The preliminary application of the SBO technique to optimize the secondary controller gains.

- Sensitivity evaluation for the proposed cascaded ID-PD controller.

Objectives

Based on the above discussion, the objectives of this work are as follows;

1. To design a hybrid deregulated power system integrated with renewable energy sources for LFC operation.

2. To apply the SBO technique in optimizing several secondary controller gains viz PID, PIDD and cascaded ID-PD.

3. To choose the optimal secondary controller among those mentioned in (2) .

4. To check the influence of geo-thermal and solar-thermal-systems on dynamic stability of the power system.

5. To investigate the system performance in presence of an SMES device.

6. To validate the resilience of the proposed cascaded ID -PD controller gains for erratic load perturbations, variations in system loading, inertial constant $(\mathrm{H})$ and changes in DISCO involvement matrix (DIM).

\section{Power System Under Examination}

A linked two-area based hybrid deregulated power system with an area capacity ratio of 1:3 is under examination. Each area is incorporated with two GENCOs. Area-1 comprises the geo-thermal (GT) and conventional thermal plant, while as area-2 comprises the solar-thermal-system (STS) and conventional thermal pant. The proposed system is provided with an applicable system non-linearities viz rate-constraint and dead-band for the thermal system. A time delay of $0.5 \mathrm{~s}$ is provided in STS units for a realistic approach. The layout of considered restructured power system is displayed in Figure 1a, while Figure $1 \mathrm{~b}$ displays its linearized transfer function (TF) model. Figure 1c,d shows both areas involvement in power contracts as per their area involvement factor (aif). The 'aif' for GENCOs is determined by the generation schedule. ACE is area control error, which is input to the secondary controller. The system nominal values are taken from $[1,12,21]$ and are mentioned in Appendix A. MATLAB software is applied to design a model and execute codes. The objective function for developed power system is taken as an integral squared 
error (ISE), as shown in Equation (1). The parameters represent their usual notations, as mentioned in the Nomenclature.

$$
I S E=\int_{0}^{T}\left(\Delta f_{1}^{2}+\Delta f_{2}^{2}+\Delta P_{\text {tie-error }}^{2}\right) d t
$$

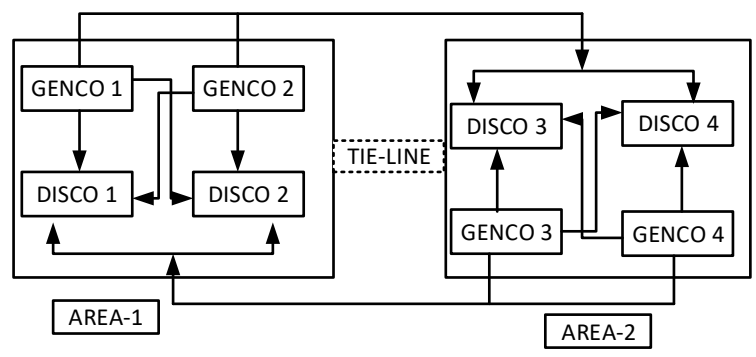

(a)

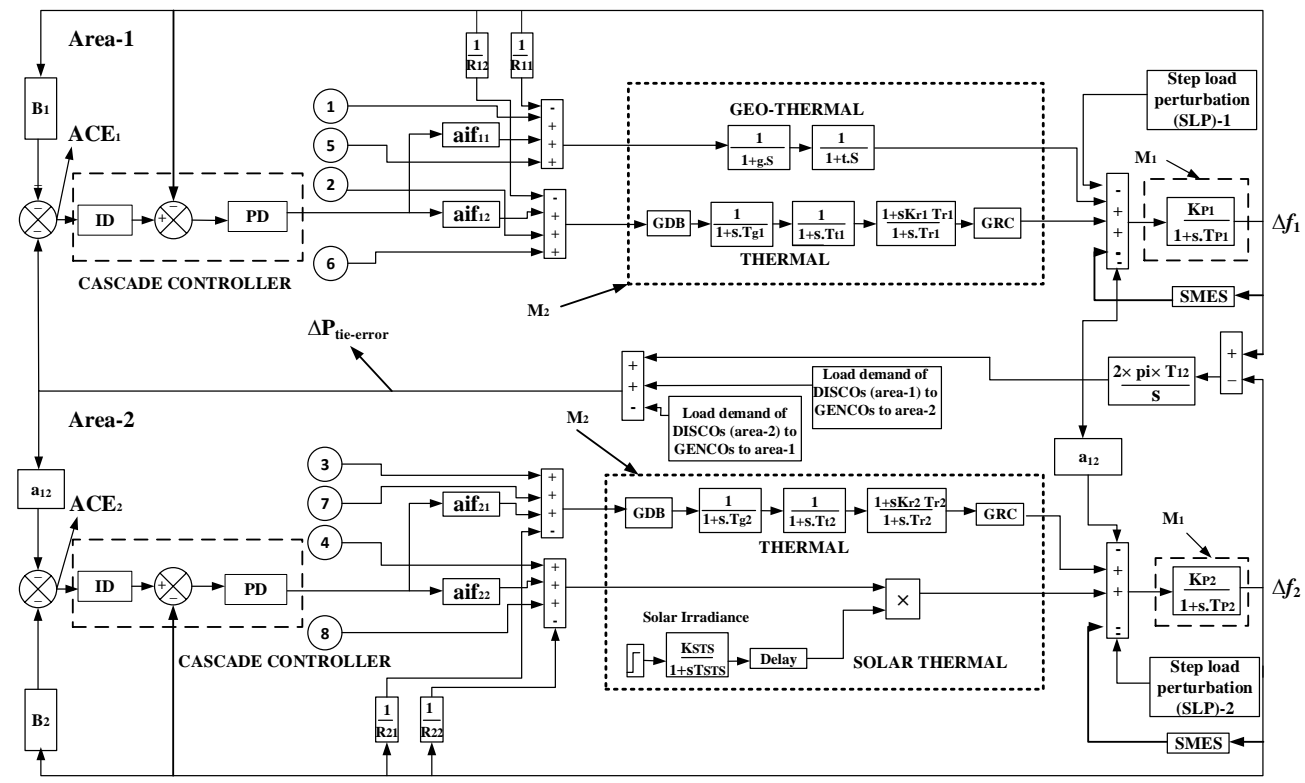

(b)

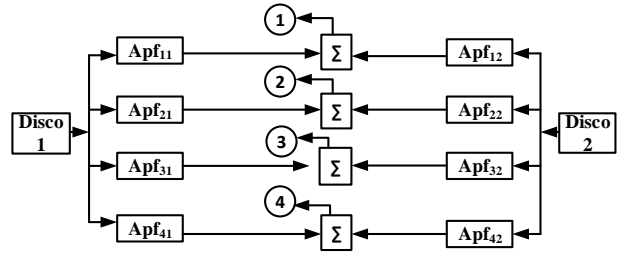

(c)

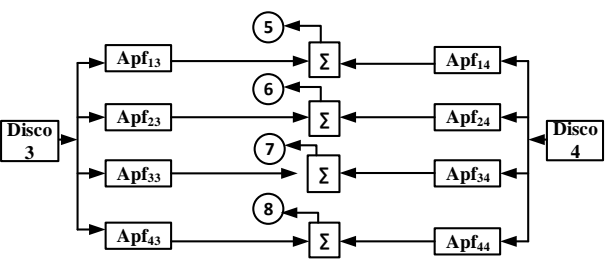

(d)

Figure 1. Modelling of two-unequal-area deregulated power system. (a) Layout of the deregulated power system. (b) Transfer function (T.F) model. (c) Area-1 power contract participation as per their 'aif'. (d) Area-2 power contract participation as per their 'aif'.

Superconducting Magnetic Energy Storage (SMES) Modelling

SMES device store power in the shape of magnetic field (MF) of a coil. The coil's MF is built of a superconducting wire with minimum energy loss. SMES can mitigate the large amount of power emitted by the power system, thereby preventing fast power loss. SMES comprises many components viz, AC/DC converter, step-down transformer, DC superconducting inductor, inductor converter unit. Since all components of the SMES unit are stationary, its endurance outperforms that of other ESDs. The charged superconducting coil carries a current and is submerged in liquid helium to keep the temperature very low. 
However, in response to increase in load demand, the stored energy is quickly released to the grid. The SMES transfer function (T.F) is given in Equation (2).

$$
T F_{S M E S}=\frac{K_{S M E S}}{T_{S M E S}+1}
$$

\section{Satin Bowerbird Optimizer (SBO) Technique}

SBO technique is reported by Moosavi et. al. [36]. Satin bowerbirds are plant and insect-eating passerines found only in the mesic forests of Australia. Bowers are built by male satin bowerbird, which are special wooden nests used for mating and intercourse. The bowers are adorned with florals, berries, and other accents. Male mating behavior includes the presentation of decorations and dancing displays, which are preceded by loud sounds, and females prefer mates who indulge in high-intensity shows. The SBO technique performed well on different test functions. Moreover, the SBO technique showed more promising results than other optimization techniques. The equations for using the SBO technique are reported in Equations (3)-(7).

$$
\begin{gathered}
\operatorname{prob}_{i}=\frac{f i t_{i}}{\sum_{n=1}^{N B} f i t_{i}} \\
f_{i t}=\left\{\begin{array}{l}
\frac{1}{1+f\left(x_{i}\right)}, f\left(x_{i}\right) \geq 0 \\
1+\left|f\left(x_{i}\right)\right|, f\left(x_{i}\right)<0
\end{array}\right. \\
X_{i k}^{\text {old }}=\lambda_{k}+\left(\left(x_{j k}+x_{\text {elite }, k} / 2\right)-X_{i k}^{\text {old }}\right) \\
\lambda_{k}=\frac{\alpha}{1+p_{j}} \\
N\left(X_{i k}^{\text {old }}, \sigma^{2}\right)=X_{i k}^{\text {old }}+\left(\sigma^{*} N(0,1)\right)
\end{gathered}
$$

The pseudo-code for $\mathrm{SBO}$ technique is mentioned below:

1: Random initialization of bowers;

2: Determine the bowers cost;

3: Determine the perfect bower and consider it elite;

4: While the end criteria is not met;

5: Estimate the bowers probability utilizing Equations (3) and (4);

6: For each bower:

7: $\quad$ For each element of bower;

8: $\quad$ Estimate $\lambda_{k}$ utilizing Equation (6);

9: $\quad$ Modify the location of bowers utilizing Equations (5) and (7) ;

10: $\quad$ End for

11: End for

12: Determine the total cost of all bowers;

13: Update elite if a bower have become more fit than elite;

14: End while;

15: Return best bower.

The secondary controller gains are optimized using SBO technique to attain the minimum ISE value given by (1) with reference to the constraints, ensuring that the power system stability is given in Equation (8).

$$
\begin{array}{r}
I_{g i}^{\min }(0) \leq I_{g i} \leq I_{g i}^{\max }(3) \\
D_{g i}^{\min }(0) \leq D_{g i} \leq D_{g i}^{\max }(3) \\
P_{g i}^{\min }(0) \leq P_{g i} \leq P_{g i}^{\max }(3) \\
N_{i}^{\min }(0) \leq N \leq N_{i}^{\max }(100)
\end{array}
$$


where $P_{g}$ is the proportional gain, $I_{g}$ is the integral gain, $D_{g}$ is the derivative gain and $N$ is the filter coefficient of the secondary controller.

\section{Secondary Controller for the Presented Deregulated Hybrid Power System}

According to the literature, to establish an effective secondary controller for the LFC operation of a modern power system, the following requirements must be addressed [2].

1. Efficient in dealing with load fluctuations.

2. Capable of dealing with energy storage system uncertainty.

3. Healthy enough for renewable energy source uncertainties.

4. Malleable to varying operational conditions in terms of tuning.

\subsection{Motivation for Cascaded Secondary Controller}

Proportional-integral-derivative (PID) is the basic controller used for industrial purposes [37]. However, PID suffers from the limitation of noise non-tolerance due to the complexity in a single derivative control [37]. To properly handle the influence of non-linearities in a sensitive system, additional derivative control action is required. Additional derivative action is used by [32] in the PID controller for the LFC operation of a hybrid power system. The results obtained with the PIDD controller showed a great enhancement in system dynamics in contrast to the PID controller [32]. In this view, the double-derivative (PIDD)based controlling strategy is integrated into the proposed power system to overcome the drawbacks in the PID controller. Furthermore, various reports in the literature $[31,33,34]$ used an advanced controller action in the shape of a cascade combination (fractional order, PD-PID and PI-PD) for power system operation. This encourages the authors to analyze the proposed power system with a cascade combination of the PIDD controller as integral derivative-proportional derivative (ID-PD). The cascade controllers effectively deal with system uncertainties by developing a advanced control action [33,34]. Hence, the secondary controllers discussed above are incorporated into the deregulated power system, one by one.

\subsection{Cascaded Integral Derivative-Proportional Derivative (Cascaded ID-PD) Controller}

The basis for cascaded controllers comes from continuous processes in which the output of the inner-loop feeds the outer-loop input. Moreover, the measurement variables are linked to both the system's outside and inner loops. The following are the characteristics of cascaded controllers, as cited in [34].

1. The inner measurement minimizes the effects of disruptions applied in sequence to the outer process.

2. The measurement of outer processes controls the final output characteristics.

The primary goal of the cascade control is to respond quickly to disturbances before they propagate to other parts of the plant. The block diagram of a cascaded ID-PD controller is depicted in Figure 2. The transfer functions of ID and PD controllers are given in (9) and (10). The outer loop $M_{1}(s)$ of the cascaded ID-PD controller represents the plant under control. During load disturbances $d(s)$, the outer loop is supposed to keep track of the reference $A C E(s)$. Hence, the present analysis applies the ID controller in its outer loop. The inner loop $M_{2}(s)$ consists of multiple generating units, also known as a secondary loop. The internal loop's primary goal is to reduce the influence of system modeling and increase control system performance by controlling gain variation. The inner loop requires erratic disruptions with high $P_{g}$ and $D_{g}$ controller terms. Equation (11) presents the transfer function of the cascaded ID-PD controller displayed in Figure 2. 


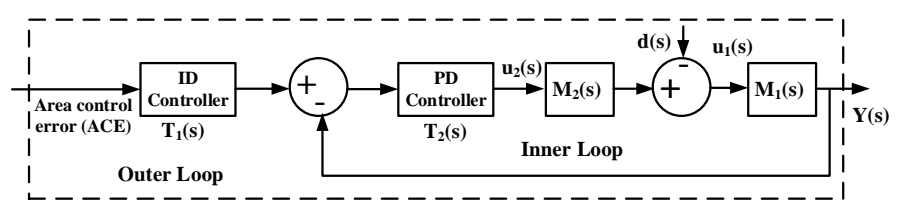

Figure 2. Block diagram of cascaded ID-PD controller.

$$
\begin{gathered}
T_{1} s=\frac{I_{g i}(s)}{s}+\frac{s D_{g i}(s)}{\frac{1}{s N_{i}+1}} \\
T_{2} s=P_{g i}(s)+\frac{s D_{g i}(s)}{\frac{1}{s N_{i}+1}} \\
Y(s)=\left[\frac{M_{1}(s) M_{2}(s) T_{1}(s) T_{2}(s)}{1+M_{1}(s) M_{2}(s) T_{2}(s)}\right] A C E(s)+\left[\frac{M_{1}(s)}{1+M_{1}(s) M_{2}(s) T_{2}(s)}\right] d(s)
\end{gathered}
$$

\section{Result and Discussion}

\subsection{Selection of Optimal Controller in Bilateral Transaction of Deregulated Power Market}

The bilateral transaction of the deregulated power market is examined to report the optimal controller, as the bilateral power transaction mode is practically applicable to power exchanges between GENCOs and DISCOs [26]. The GENCOs in bilateral transactions are free to participate in power contracts with DISCOs. Donde's concept [26] of developing a DISCO-involvement-matrix (DIM) is utilized in this study. The DIM for the developed power system (Figure 1a) is depicted in Equation (12). The rows and columns in DIM depict the number of GENCOs and DISCOs present in the system. The DIM elements are called agreement participation factors (Apf). The power agreement between GENCOs and DISCOs can be understood from the considered DIM.

$$
D I M=\left[\begin{array}{llll}
A p f_{11} & A p f_{12} & A p f_{13} & A p f_{14} \\
A p f_{21} & A p f_{22} & A p f_{23} & A p f_{24} \\
A p f_{31} & A p f_{32} & A p f_{33} & A p f_{34} \\
A p f_{41} & A p f_{42} & A p f_{43} & A p f_{44}
\end{array}\right]
$$

As power exchanges in bilateral transactions are applicable to the same area, the DIM $M_{\text {Bilateral }}$ reported in (13) are legitimate to that particular area. For each DISCO, the load demand of $0.01 p u M W$ is considered. Therefore, $2 \%$ of the load demand is chosen for area- 1 and area-2. The calculation of area involvement factors (aifs) is based on the procedure given by [23]. The aifs were calculated corresponding to the entries mentioned in DIM Bilateral are aif $_{11}=0.4$, aif $f_{12}=0.6$, aif $f_{21}=0.425$, aif $f_{22}=0.575$. In this study, several secondary controllers (PID, PIDD, cascaded PI-PD and cascaded ID-PD) were individually examined for the LFC operation of a deregulated hybrid power system. SBO technique is effectively used to optimize the secondary controller gains. The dynamic responses of each controller, considered one at a time, were obtained and evaluated for comparison to check the impact of each controller in improving the frequency or tie-line power deviations, displayed in Figure 3. Table 1 reports the optimized gains for each controller. The optimized gains of each controller, shown in Table 1, are the optimal gains that were found with reference to the miniumum ISE value (objective function) achieved. The detailed examination of Figure 3 depicts very encouraging results for the cascaded ID-PD controller in terms of improvements in the frequency or tie-line power variations. Further, the values in Tables 1 and 2 confirm the dominance of the cascaded ID-PD controller in terms of ISE values, peak deviations and settling time. In Table 2, PU is the peak undershoot (minimum value of the 
response), $\mathrm{PO}$ is the peak overshoot (maximum value of the response) and ST is the settling time (settling time of the response).

$$
\text { DIM }_{\text {Bilateral }}=\left[\begin{array}{cccc}
0.15 & 0.25 & 0.2 & 0.2 \\
0.35 & 0.25 & 0.3 & 0.3 \\
0.2 & 0.3 & 0.15 & 0.2 \\
0.3 & 0.2 & 0.35 & 0.3
\end{array}\right]
$$

Validation of SBO technique: The SBO technique in adjusting optimal secondary controller (cascaded ID-PD) is examined with other existing optimization techniques (OTs). The developed hybrid deregulated power system is simulated with various OTs viz particle swarm optimization (PSO), grey wolf optimization (GWO) and firefly algorithm (FA). The convergence curve attained with reference to the aforementioned OTs in Figure 4a exposes the minimum value for the SBO technique. Moreover, the frequency deviation $\left(\Delta f_{1}\right)$ attained in Figure $4 \mathrm{~b}$ for each OT reveals that SBO-adjusted cascaded ID-PD controller shows a considerably improved performance in contrast to the other OTs.

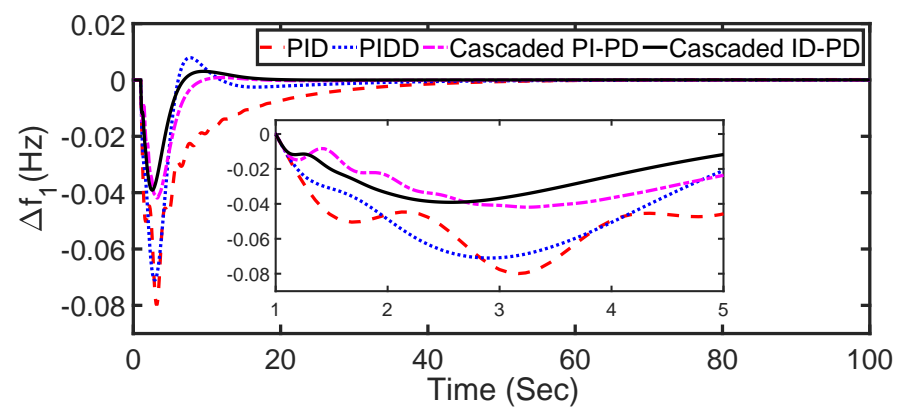

(a) $\Delta f_{1}$

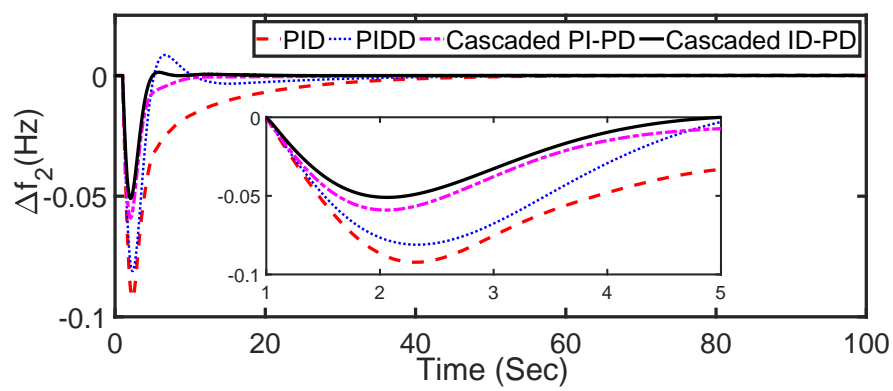

(b) $\Delta f_{2}$

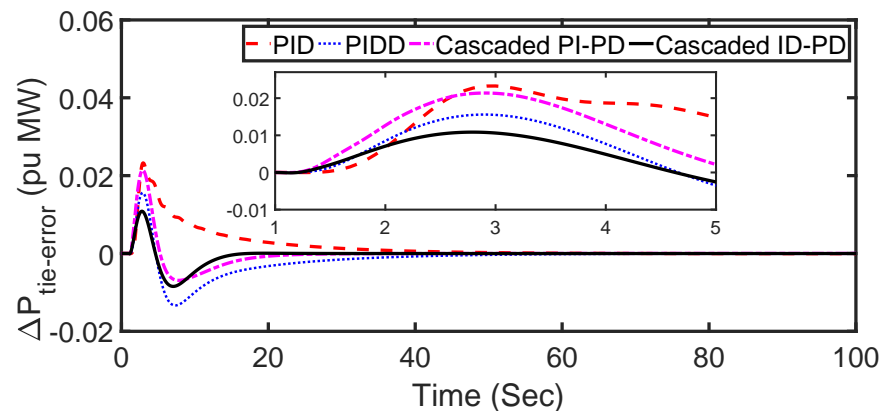

(c) $\Delta P_{\text {tie-error }}$

Figure 3. Comparison of dynamic responses for several SBO-optimized secondary controllers. 
Table 1. SBO-optimized gains \& ISE values for different secondary controllers.

\begin{tabular}{|c|c|c|c|c|c|c|c|c|c|}
\hline \multirow[b]{2}{*}{ Controller } & \multicolumn{2}{|c|}{$P_{g}$} & \multicolumn{2}{|c|}{$I_{g}$} & \multicolumn{2}{|c|}{$D_{g}$} & \multicolumn{2}{|c|}{$N$} & \multirow[b]{2}{*}{ ISE } \\
\hline & $\begin{array}{l}P_{g 11} \\
P_{g 12}\end{array}$ & $\begin{array}{l}P_{g 21} \\
P_{g 22}\end{array}$ & $I_{g 1}$ & $I_{g 2}$ & $\begin{array}{l}D_{g 11} \\
D_{g 12}\end{array}$ & $\begin{array}{l}D_{g 21} \\
D_{g 22}\end{array}$ & $\begin{array}{l}N_{11} \\
N_{12}\end{array}$ & $\begin{array}{l}N_{21} \\
N_{22}\end{array}$ & \\
\hline PID & 0.63 & 1.54 & 1.39 & 0.25 & 0.26 & 0.18 & 0.78 & 42.31 & 0.019964 \\
\hline PIDD & 0.86 & 0.87 & 0.23 & 1.62 & $\begin{array}{l}0.64 \\
0.49\end{array}$ & $\begin{array}{l}0.68 \\
0.75\end{array}$ & $\begin{array}{l}49.18 \\
50.61\end{array}$ & $\begin{array}{l}35.62 \\
33.19\end{array}$ & 0.016627 \\
\hline Cascaded PI-PD & $\begin{array}{l}0.65 \\
1.33\end{array}$ & $\begin{array}{l}0.59 \\
1.15\end{array}$ & 0.59 & 1.21 & 1.51 & 0.75 & 21.60 & 79.04 & 0.010023 \\
\hline Cascaded ID-PD & 0.88 & 1.27 & 0.96 & 2.09 & $\begin{array}{l}1.91 \\
0.31\end{array}$ & $\begin{array}{l}0.23 \\
1.65\end{array}$ & $\begin{array}{l}37.76 \\
10.77\end{array}$ & $\begin{array}{l}62.38 \\
21.49\end{array}$ & 0.007547 \\
\hline
\end{tabular}

Table 2. Observations of Figure 3.

\begin{tabular}{ccccc}
\hline Parameter & Controller & PU & PO & ST \\
\hline \multirow{4}{*}{$\Delta f_{1}$} & PID & -0.0799 & 0.00014 & 58.38 \\
& PIDD & -0.0710 & 0.00791 & 42.2 \\
& Cascaded PI-PD & -0.0419 & 0.00105 & 19.82 \\
& Cascaded ID-PD & -0.0391 & 0.00305 & 17.1 \\
\hline \multirow{4}{*}{$\Delta f_{2}$} & PID & -0.0922 & 0.00014 & 58.3 \\
& PIDD & -0.0810 & 0.00851 & 43.32 \\
& Cascaded PI-PD & -0.0598 & 0.00131 & 18.17 \\
& Cascaded ID-PD & -0.0509 & 0.00138 & 15.79 \\
\hline \multirow{5}{*}{$\Delta P_{\text {tie-error }}$} & PID & $-5.8 \times 10^{-5}$ & 0.02328 & 60.39 \\
& PIDD & -0.0133 & 0.01559 & 52.1 \\
& Cascaded PI-PD & -0.0079 & 0.02138 & 22.73 \\
& Cascaded ID-PD & -0.0084 & 0.01085 & 16.8 \\
\hline
\end{tabular}

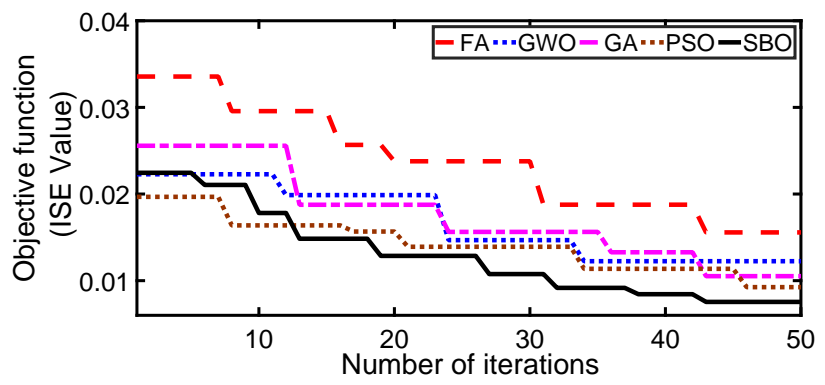

(a) Convergence characteristics

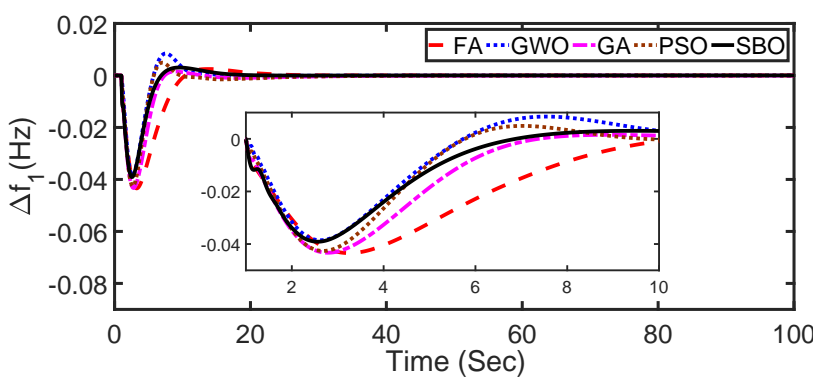

(b) $\Delta f_{1}$

Figure 4. Comparison of SBO technique with other optimization techniques.

\subsection{Effect of Renewable-Energy-Sources (RES) on System Dynamics}

In this analysis, the impact of RES on system dynamics is examined. The proposed system is provided with an optimal cascaded ID-PD controller using the same gains as attained under nominal conditions (Table 1). Under this condition, this system is simulated for different combinations to reflect the impact of RES. In this analysis, the geo-thermal plant in area- 1 is disconnected from the system and the responses are obtained, as presented in Figure 5. Then, solar-thermal-system (STS) is disconnected from power system and the obtained responses are presented in Figure 5. The responses attained with these combinations are compared to check the effectiveness of RES on the system dynamics. The critical inspection of Figure 5 exposes that a significant improvement in transient and steady-state dynamics of the power system in the presence of RES. This is because RES possess smaller kinetic and electrical inertia in contrast to large conventional rotating generating units [2]. 


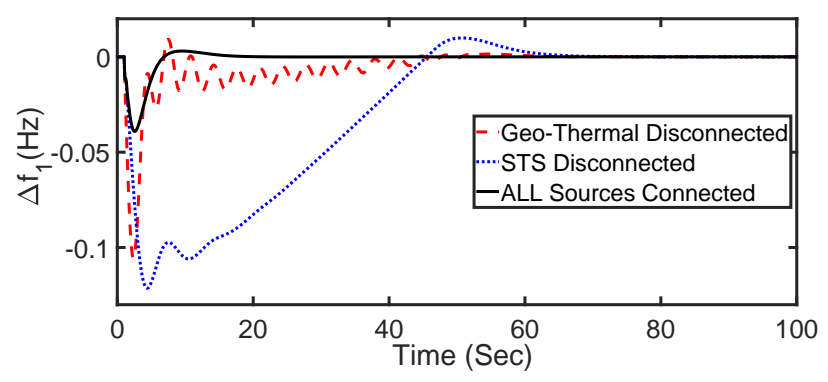

(a) $\Delta f_{1}$

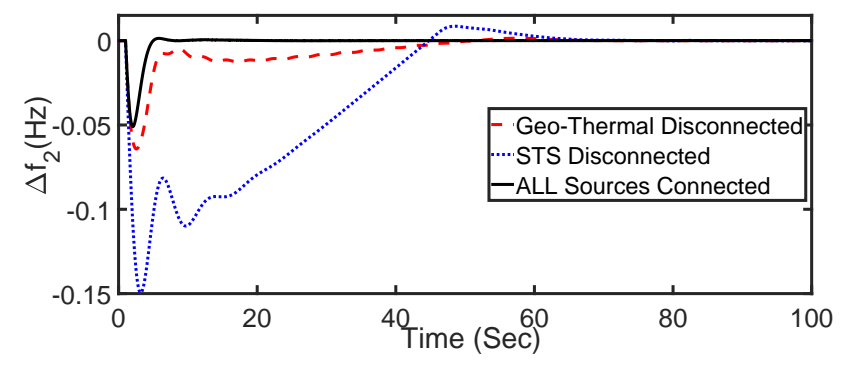

(b) $\Delta f_{2}$

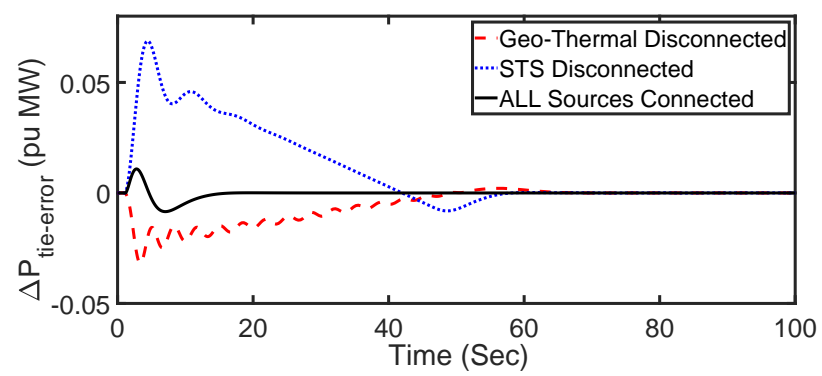

(c) $\Delta P_{\text {tie-error }}$

Figure 5. Comparison of dynamic responses for SBO-optimized cascaded ID-PD controller in the presence and absence of RES.

\subsection{System Performance with Super-Conducting-Magnetic-Energy-Storage (SMES) Device}

As more renewable energy sources (RES) are chosen as generation sources, energy storage devices (ESD) are becoming more prevalent in today's power systems. ESDs have a strong capacity to decrease frequency oscillations and stabilize the systems that have been affected by system transients [15]. Therefore, the deregulated hybrid power system is provided with SMES in both areas. The location of SMES in both areas can be seen from Figure $1 b$, as SMES have an almost negligible maintenance, a rapid charging/discharging rate, increased power density, etc. [19]. The power system is simulated in presence of an optimal cascaded ID-PD controller. The dynamic responses for an SMES incorporated deregulated power system are attained and presented in Figure 6, while the optimized gains in the cascaded ID-PD controller are reported in Table 3. A critical inspection of Figure 6 infers the desired performance of deregulated power system in presence of the SMES device. Moreover, the Table 4 confirms better performance of the SMES device in terms of peak deviations and settling time. 


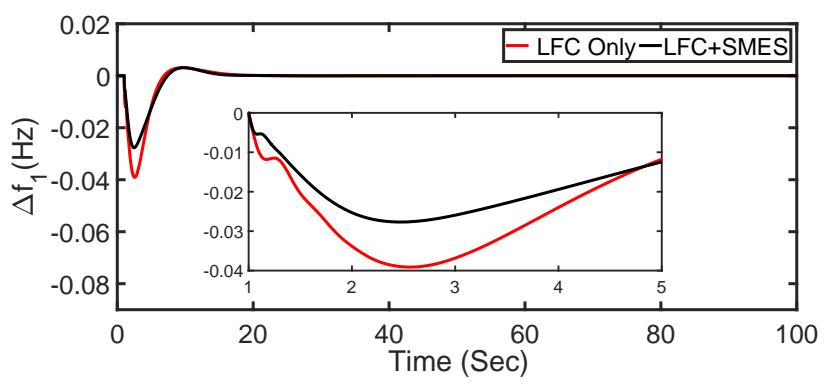

(a) $\Delta f_{1}$

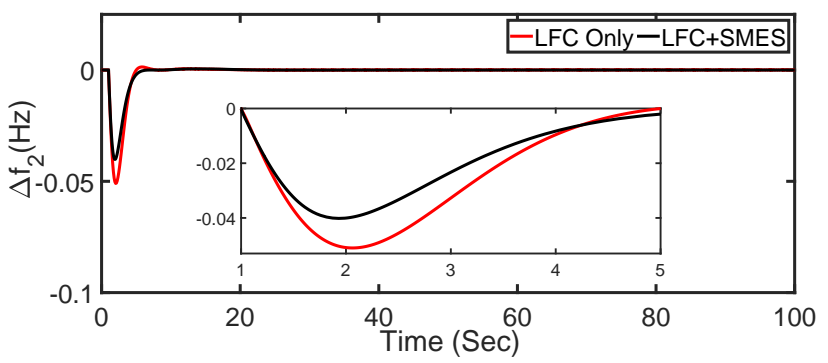

(b) $\Delta f_{2}$

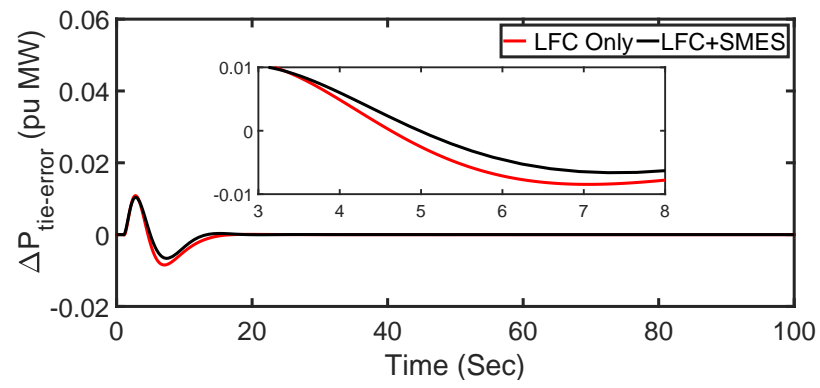

(c) $\Delta P_{\text {tie-error }}$

Figure 6. Comparison of dynamic responses for SBO-optimized cascaded ID-PD controller in the presence and absence of SMES.

Table 3. Cascaded ID-PD-controller-optimized gains in the presence of SMES.

\begin{tabular}{ccccc}
\hline $\begin{array}{c}\text { Proportional gain } \\
\text { Value }\end{array}$ & $P_{g 1}$ & $P_{g 2}$ & & \\
\hline Integral gain & 1.35 & 2.51 & & \\
Value & $I_{g 1}$ & $I_{g 2}$ & & \\
\hline Derivative gain & 1.06 & 1.11 & & $D_{g 22}$ \\
Value & $D_{g 11}$ & $D_{g 12}$ & $D_{g 21}$ & 1.16 \\
\hline $\mathrm{N}$ & 1.36 & 0.74 & 0.48 & $N_{22}$ \\
Value & $N_{11}$ & $N_{12}$ & $N_{21}$ & 44.3 \\
\hline
\end{tabular}

Table 4. Observations of Figure 6.

\begin{tabular}{ccccc}
\hline Combination & Controller & PU & PO & ST \\
\hline \multirow{2}{*}{$\Delta f_{1}$} & LFC Only & -0.0391 & 0.00305 & 17.1 \\
& LFC+SMES & -0.0276 & 0.003 & 15.98 \\
\hline \multirow{2}{*}{$\Delta f_{2}$} & LFC only & -0.0509 & 0.00138 & 15.79 \\
& LFC+SMES & -0.0401 & 0.00051 & 14.32 \\
\hline \multirow{2}{*}{$\Delta P_{\text {tie-error }}$} & LFC Only & -0.0084 & 0.01085 & 16.8 \\
& LFC+SMES & -0.0066 & 0.0103 & 16.5 \\
\hline
\end{tabular}

\subsection{Sensitivity Evaluation (SE)}

The dynamic behaviour of hybrid power system is tested when it undergoes some changes in system parameters under nominal conditions using a sensitivity evaluation. The authors aimed to check the optimal controller's robustness by changing some of the system parameters in this study.

\subsubsection{Random Load Perturbation (RLP)}

To inspect the sensitivity evaluation of the proposed cascaded ID-PD controller, the hybrid power system is subjected to an intense variation in load changes in both areas, as 
shown in Figure 7a. The dynamic responses pertaining to random load changes are attained, and presented in Figure $7 \mathrm{~b}-\mathrm{d}$. The red colour responses (Offline responses) in Figure $7 \mathrm{~b}-\mathrm{d}$ refer to the responses attained using already-optimized cascaded ID-PD controller gains (Table 1) under nominal system conditions. The black colour responses (Real-time responses) refer to the responses attained using newly optimized cascaded ID-PD controller gains, as shown in (Table 5). The observations from Figure $7 \mathrm{~b}-\mathrm{d}$ infer the strength of the cascaded ID-PD controller against the random load changes, as offline and real-time responses are the same.

Table 5. Cascaded ID-PD-controller-optimized gains for random load changes in both areas.

\begin{tabular}{ccccc}
\hline $\begin{array}{c}\text { Proportional Gain } \\
\text { Value }\end{array}$ & $P_{g 1}$ & $P_{g 2}$ & & \\
\hline Integral gain & 0.79 & 1.32 & & \\
Value & $I_{g 1}$ & $I_{g 2}$ & & \\
\hline Derivative gain & 1.02 & 1.98 & & $D_{g 22}$ \\
Value & $D_{g 11}$ & $D_{g 12}$ & $D_{g 21}$ & 1.56 \\
\hline $\mathrm{N}$ & 1.8356 & 0.29 & 0.20 & $N_{22}$ \\
Value & $N_{11}$ & $N_{12}$ & $N_{21}$ & 70.38 \\
\hline
\end{tabular}

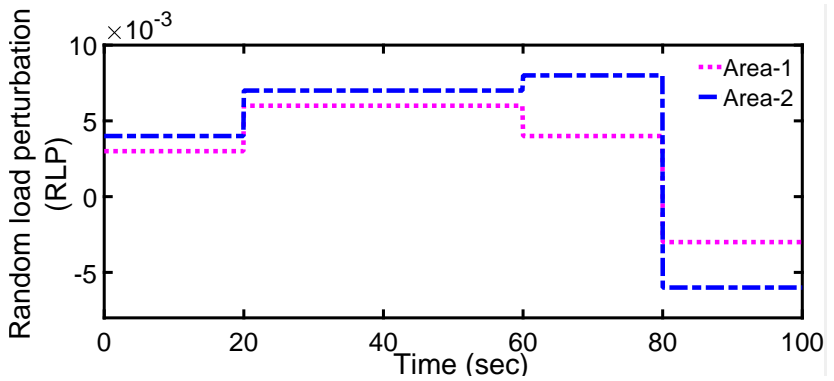

(a) Random load variations in both areas

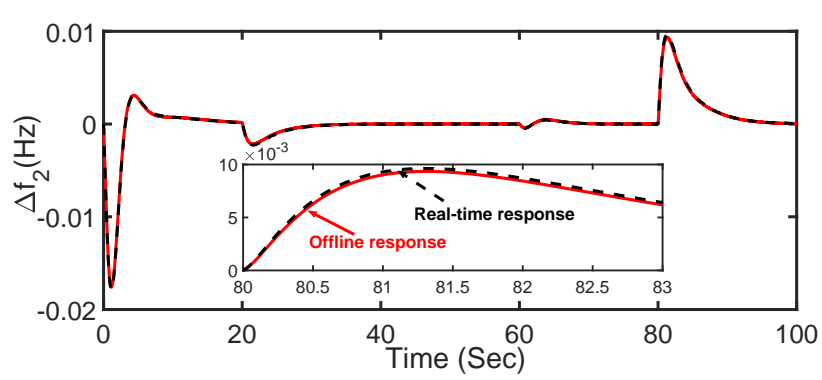

(c) $\Delta f_{2}$

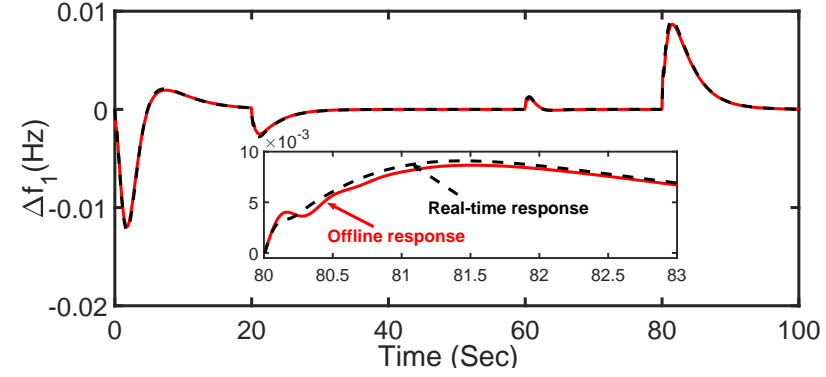

(b) $\Delta f_{1}$

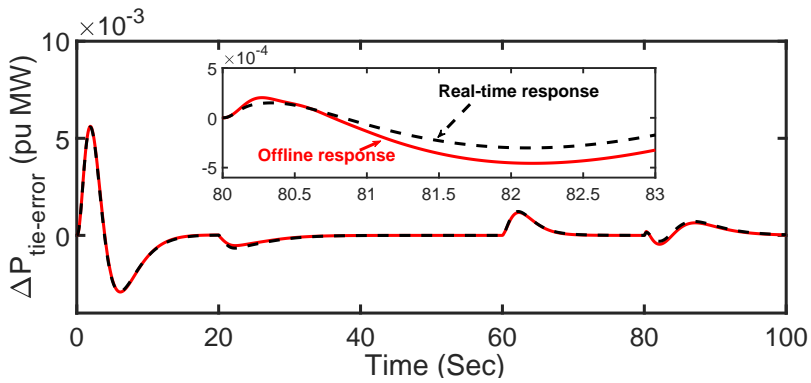

(d) $\Delta P_{\text {tie-error }}$

Figure 7. Comparison of offline and real-time SBO-optimized dynamic responses for cascaded ID-PD controller for random load variations.

\subsubsection{System Loading Variation}

In this section of $\mathrm{SE}$, the developed hybrid power system is subjected to variations in the system loading of $( \pm 20 \%)$ from a nominal loading of $50 \%$. The dynamic responses with respect to $30 \%$ and $70 \%$ system loading's are achieved, and presented in Figure 8 and 9. Tables 6 and 7 present the real-time optimized gains of the cascaded ID-PD controller for $30 \%$ and $70 \%$ system loading. The observations from Figure 8 and 9 show the resilience of the cascaded ID-PD controller against the system loading variations. 
Table 6. Cascaded ID-PD controller optimized gains for 30\% system loading.

\begin{tabular}{ccccc}
\hline $\begin{array}{c}\text { Proportional gain } \\
\text { Value }\end{array}$ & $P_{g 1}$ & $P_{g 2}$ & & \\
\hline Integral gain & 1.18 & 1.38 & & \\
Value & $I_{g 1}$ & $I_{g 2}$ & & \\
\hline Derivative gain & 0.87 & 1.95 & & $D_{g 22}$ \\
Value & $D_{g 11}$ & $D_{g 12}$ & $D_{g 21}$ & 1.29 \\
\hline $\mathrm{N}$ & 1.76 & 0.40 & 0.43 & $N_{22}$ \\
Value & $N_{11}$ & $N_{12}$ & $N_{21}$ & 58.39 \\
\hline
\end{tabular}

Table 7. Cascaded ID-PD controller optimized gains for 70\% system loading.

\begin{tabular}{ccccc}
\hline $\begin{array}{c}\text { Proportional gain } \\
\text { Value }\end{array}$ & $P_{g 1}$ & $P_{g 2}$ & & \\
\hline Integral gain & 0.94 & 1.23 & & \\
Value & $I_{g 1}$ & $I_{g 2}$ & & \\
\hline Derivative gain & 1.19 & 1.81 & & $D_{g 22}$ \\
Value & $D_{g 11}$ & $D_{g 12}$ & $D_{g 21}$ & 1.71 \\
\hline $\mathrm{N}$ & 1.69 & 0.38 & 0.54 & $N_{22}$ \\
Value & $N_{11}$ & $N_{12}$ & $N_{21}$ & 65.29 \\
\hline
\end{tabular}

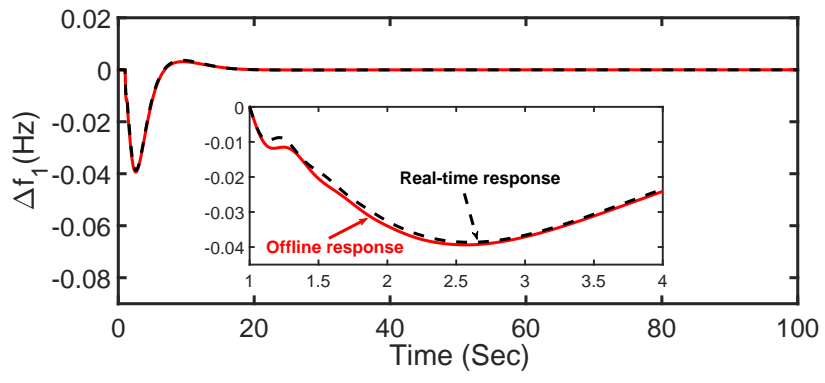

(a) $\Delta f_{1}$

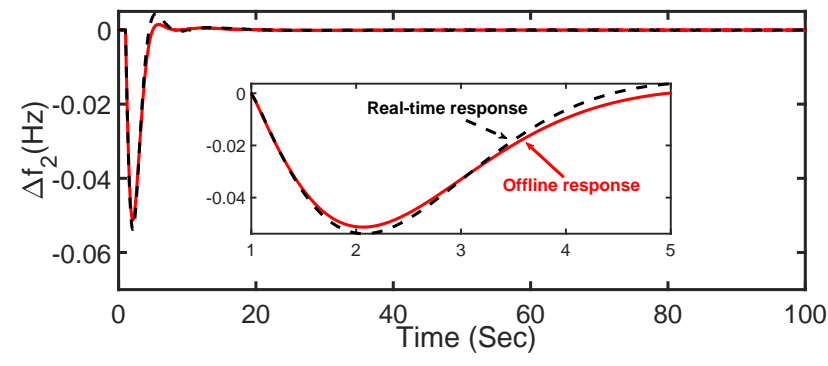

(b) $\Delta f_{2}$

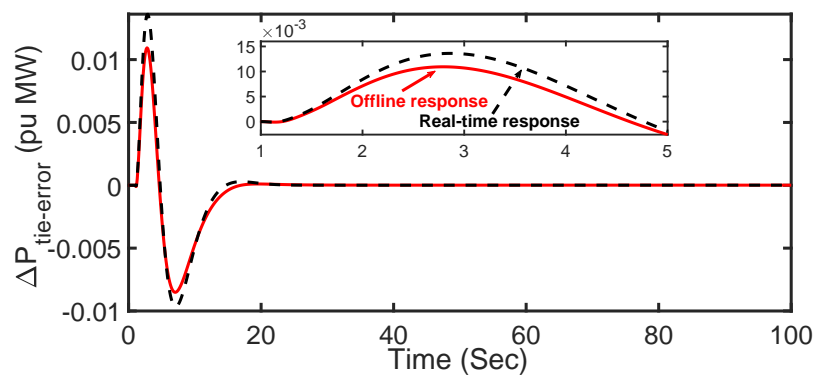

(c) $\Delta P_{\text {tie-error }}$

Figure 8. Comparison of dynamic responses for SBO optimized cascaded ID-PD controller (30\% system loading).

\subsubsection{Inertial Constant $(\mathrm{H})$ Variation}

In this analysis, the $\mathrm{H}$ parameter is varied in array of $\pm 25 \%$ from a nominal value of $5 \mathrm{~s}$. Dynamic responses pertaining to $H=3.75 \mathrm{~s}$ and $H=6.25 \mathrm{~s}$ are attained and presented in Figures 10 and 11. Tables 8 and 9 reports the real-time optimized cascaded ID-PD controller gains for variations in $\mathrm{H}$ parameter. The detailed inspection of Figures 10 and 11 clearly reveals the strength of cascaded ID-PD controller in response to variations in $\mathrm{H}$ parameter as both the real-time and offline responses are almost same. 


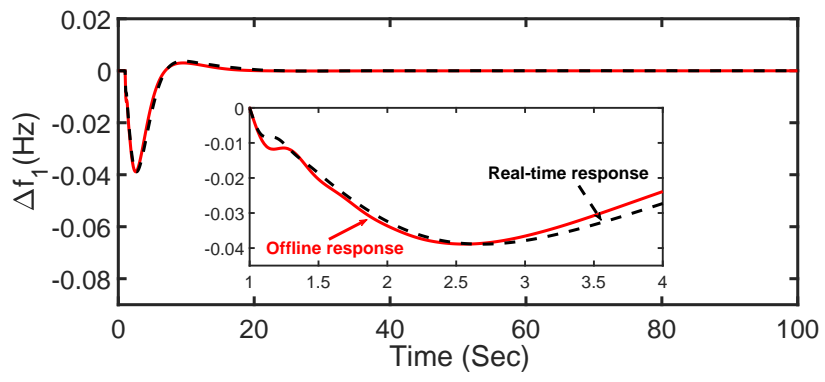

(a) $\Delta f_{1}$

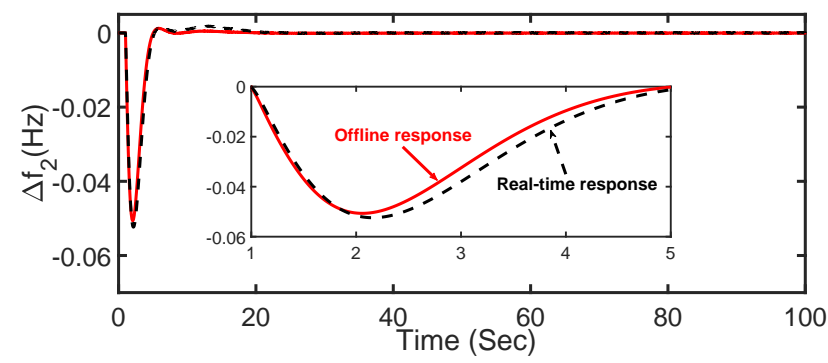

(b) $\Delta f_{2}$

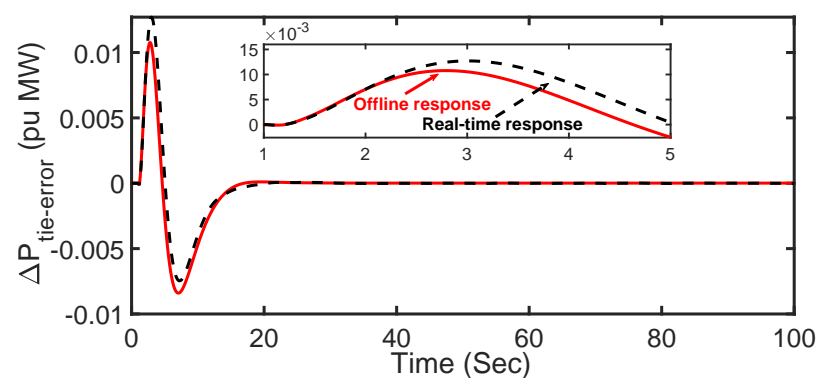

(c) $\Delta P_{\text {tie-error }}$

Figure 9. Comparison of dynamic responses for SBO-optimized cascaded ID-PD controller (70\% system loading).

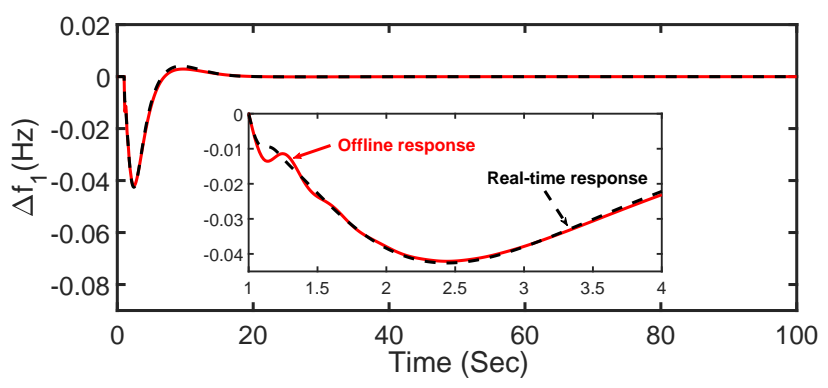

(a) $\Delta f_{1}$

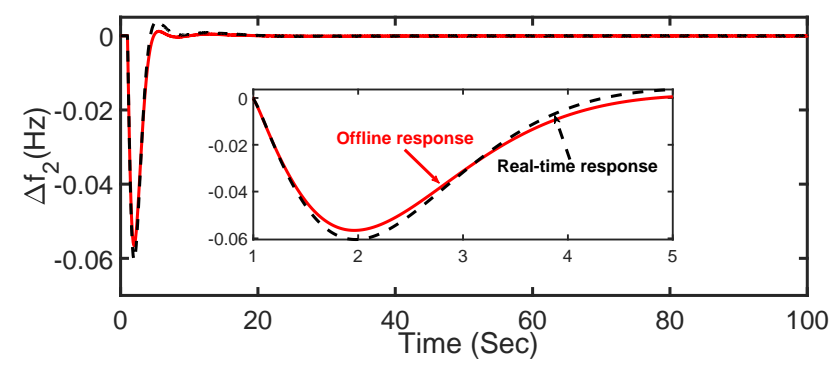

(b) $\Delta f_{2}$

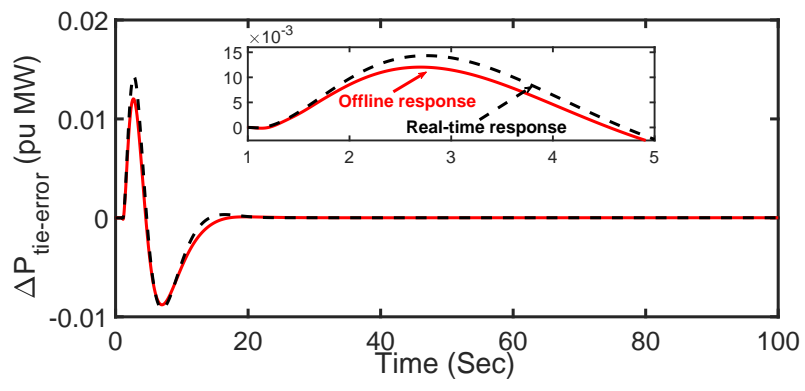

(c) $\Delta P_{\text {tie-error }}$

Figure 10. Comparison of dynamic responses for SBO-optimized cascaded ID-PD controller ( $H=3.75 \mathrm{~s})$. 


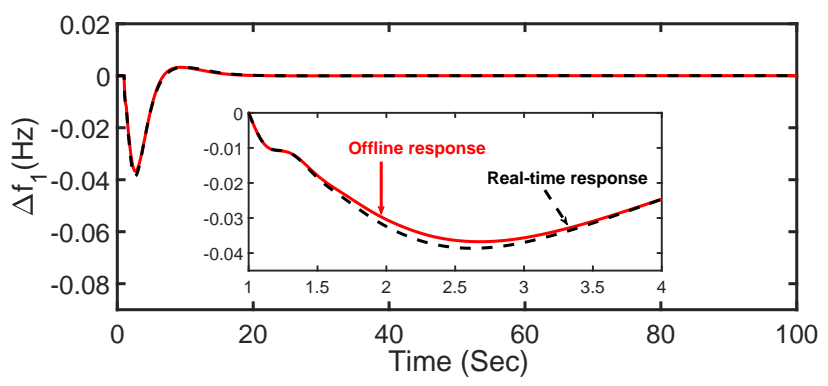

(a) $\Delta f_{1}$

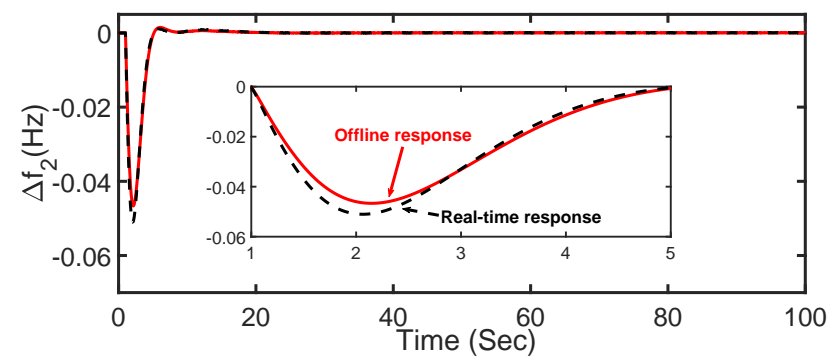

(b) $\Delta f_{2}$

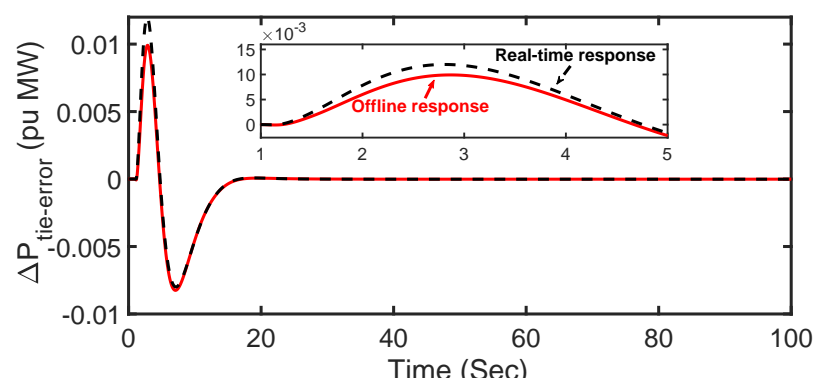

(c) $\Delta P_{\text {tie-error }}$

Figure 11. Comparison of dynamic responses for SBO-optimized cascaded ID-PD controller $(H=6.25 \mathrm{~s})$.

Table 8. Cascaded ID-PD-controller-optimized gains for $H=3.75 S$.

\begin{tabular}{ccccc}
\hline $\begin{array}{c}\text { Proportional gain } \\
\text { Value }\end{array}$ & $P_{g 1}$ & $P_{g 2}$ & & \\
\hline Integral gain & 1.07 & 1.49 & & \\
Value & $I_{g 1}$ & $I_{g 2}$ & & \\
\hline Derivative gain & 1.03 & 1.68 & & $D_{g 22}$ \\
Value & $D_{g 11}$ & $D_{g 12}$ & $D_{g 21}$ & 1.22 \\
\hline $\mathrm{N}$ & 1.87 & 0.29 & 0.38 & $N_{22}$ \\
Value & $N_{11}$ & $N_{12}$ & $N_{21}$ & 70.38 \\
\hline
\end{tabular}

Table 9. Cascaded ID-PD-controller-optimized gains for $H=6.25 S$.

\begin{tabular}{ccccc}
\hline $\begin{array}{c}\text { Proportional gain } \\
\text { Value }\end{array}$ & $P_{g 1}$ & $P_{g 2}$ & & \\
\hline Integral gain & 0.99 & 1.16 & & \\
Value & $I_{g 1}$ & $I_{g 2}$ & & \\
\hline Derivative gain & 0.96 & 2.09 & & $D_{g 22}$ \\
Value & $D_{g 11}$ & $D_{g 12}$ & $D_{g 21}$ & 1.61 \\
\hline $\mathrm{N}$ & 1.91 & 0.31 & 0.23 & $N_{22}$ \\
Value & $N_{11}$ & $N_{12}$ & $N_{21}$ & 60.18 \\
\hline
\end{tabular}

\subsubsection{Deviations in Solar Irradiance}

Solar energy is readily available and intermittent in nature. To incorporate such practicality (intermittency) into the developed hybrid deregulated power system, the solar-thermal-system (STS) is supplied with more complex and random variations in solar irradiance, as shown in Figure 12a. Dynamic responses pertaining to random deviations in solar irradiance are attained, and presented in Figure $12 \mathrm{~b}-\mathrm{d}$. Table 10 reports the real-time optimized gains in changed simulated system. The observations from Figure $12 b-d$ reveal 
the strength of the cascaded ID-PD controller gains against the random deviations in solar irradiance, as offline and real-time responses are almost the same.

Table 10. Cascaded ID-PD-controller-optimized gains for random deviations in solar irradiance.

\begin{tabular}{ccccc}
\hline $\begin{array}{c}\text { Proportional gain } \\
\text { Value }\end{array}$ & $P_{g 1}$ & $P_{g 2}$ & & \\
\hline Integral gain & 0.90 & 1.18 & & \\
Value & $I_{g 1}$ & $I_{g 2}$ & & \\
\hline Derivative gain & 0.84 & 1.96 & & $D_{g 22}$ \\
Value & $D_{g 11}$ & $D_{g 12}$ & $D_{g 21}$ & 1.72 \\
\hline $\mathrm{N}$ & 1.78 & 0.42 & 0.31 & $N_{22}$ \\
Value & $N_{11}$ & $N_{12}$ & $N_{21}$ & 70.39 \\
\hline
\end{tabular}

\subsubsection{System Behaviour with DIM Changed}

As the market economy varies, the DIM may not stay same. Hence, SE is extended by applying a different DIM to inspect such a practical state in a modern-day power system, given by Equation (14).

$$
\text { DIM }_{\text {Bilateral-Changed }}=\left[\begin{array}{cccc}
0.2 & 0.2 & 0.25 & 0.25 \\
0.3 & 0.3 & 0.25 & 0.25 \\
0.25 & 0.2 & 0.2 & 0.3 \\
0.25 & 0.3 & 0.3 & 0.2
\end{array}\right]
$$

The cascaded ID-PD controller gains that were already optimized with DIM Bilateral (Nominal DIM) and reported in (Table 1) are considered in this analysis. The dynamic responses for DIM Bilateral-Changed were attained and compared with the responses attained with a nominal DIM, as presented in Figure 13. The detailed observations of Figure 13 reveal that the alterations in DIM do not have an effect on the system performance, as the responses are same for DIM Bilateral-Changed, in contrast to DIM Bilateral .

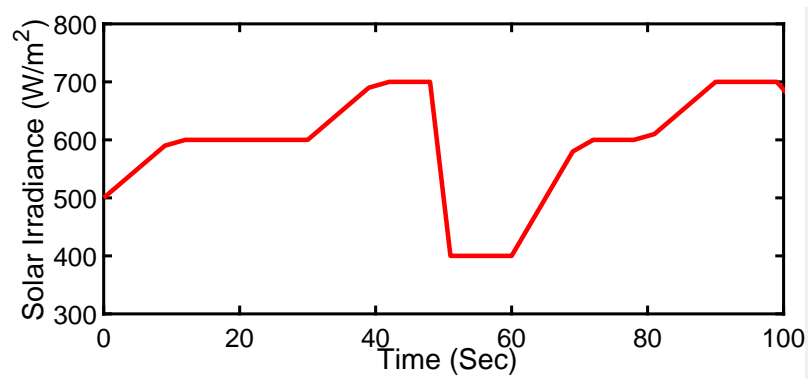

(a) Random solar irradiance

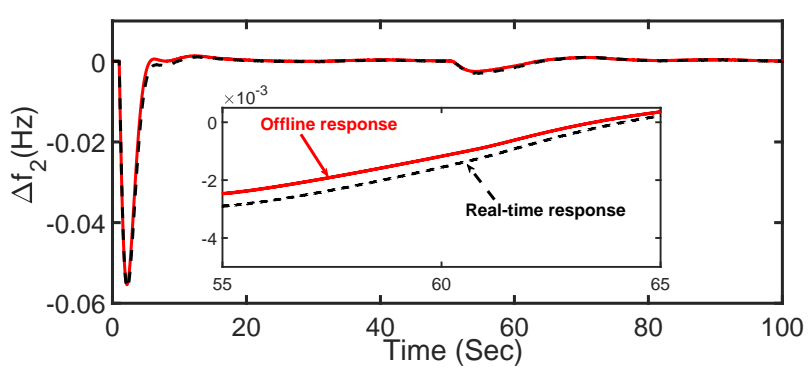

(c) $\Delta f_{2}$

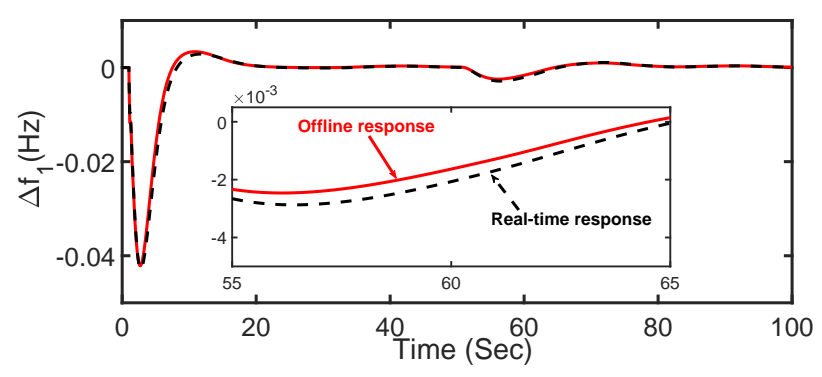

(b) $\Delta f_{1}$

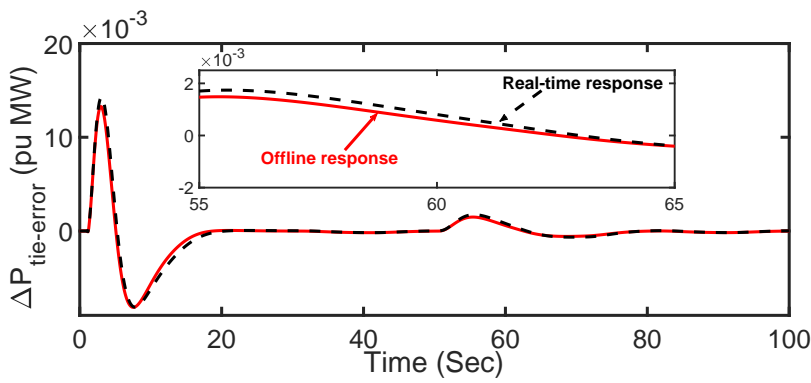

(d) $\Delta P_{\text {tie-error }}$

Figure 12. Comparison of offline and real-time, SBO-optimized dynamic responses for cascaded ID-PD controller for random deviations in solar irradiance. 


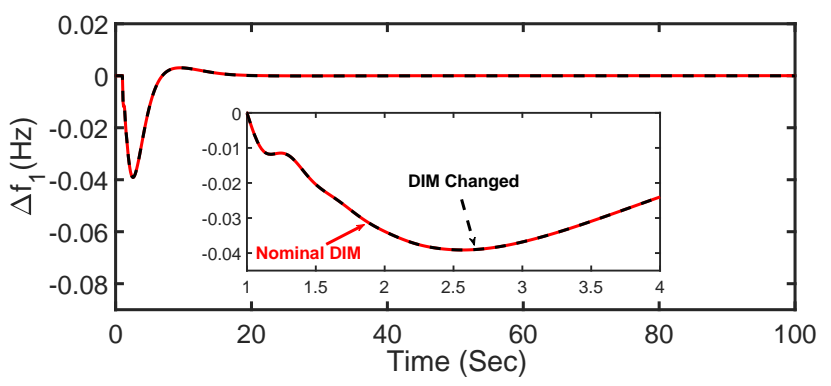

(a) $\Delta f_{1}$

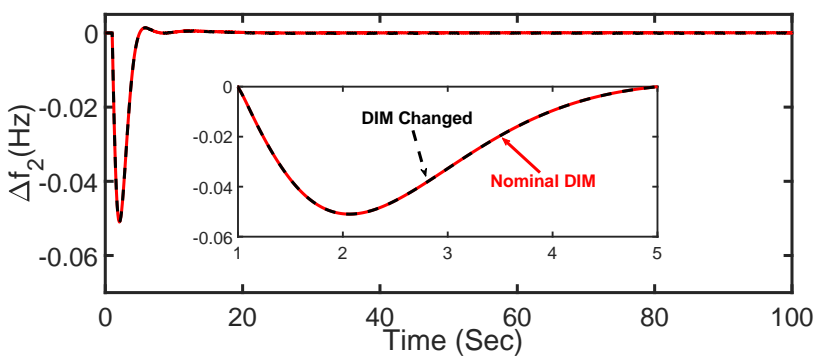

(b) $\Delta f_{2}$

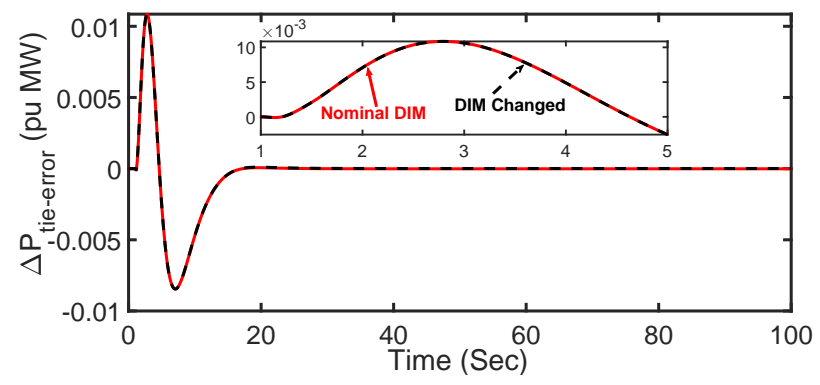

(c) $\Delta P_{\text {tie-error }}$

Figure 13. Comparison of dynamic responses for alterations in DIM.

\section{Conclusions}

The dynamic control of a renewable energy sources (RES)-based hybrid deregulated power system is investigated in this study. Different secondary controllers were effectively optimized using the satin-bowerbird optimization (SBO) technique. The system dynamic responses for the cascaded ID-PD controller are found to be impressive in improving the dynamic stability of the power system. Furthermore, it is clear from the optimal cascaded ID-PD controller that $\Delta f_{1}$ has a lesser peak-to-peak magnitude of $0.041 \mathrm{~Hz}$ against the cascaded PI-PD $(0.043 \mathrm{~Hz})$, PIDD $(0.078 \mathrm{~Hz})$ and PID $(0.079 \mathrm{~Hz})$ controller. The peak-topeak magnitude of $0.041 \mathrm{~Hz}$ resembles the frequency variation in $0.069 \%$, which is far lower than the prescribed $\pm 1 \%$ frequency variation limit.

The impact of RES in the form of geo-thermal and solar-thermal-systems regarding improvements in the system dynamics is successfully explored. The results showed a significant improvement in system dynamics, due to the reduced kinetic inertia compared to conventional generating units. Further, the incorporation of SMES device in existing optimal cascaded ID-PD controllers led to an improvement in system dynamics, with fewer deviations and an improved settling time. Moreover, the robustness of optimal controller gains is demonstrated by exposure to different system parametric alterations using a sensitivity evaluation (SE). SE discloses that the optimal cascaded ID-PD controller gains are robust for intense alterations in load perturbations, system loading, inertial constant $(\mathrm{H})$ and solar irradiance. Furthermore, the analysis with variations in the DISCO involvement matrix (DIM), which are expected in a realistic deregulated power system, reflects the healthiness of the optimised gains in the cascaded ID-PD controller that were achieved at a nominal DIM.

Author Contributions: Conceptualization, Z.F. and A.R.; methodology, Z.F., A.R. and S.M.S.H.; software, Z.F.; validation, Z.F., A.R. and S.M.S.H.; formal analysis, Z.F., A.R. and S.M.S.H.; investigation, Z.F. and A.R.; resources, A.R.; data curation, Z.F. and A.R.; writing-original draft preparation, Z.F.; writing-review and editing, A.R., S.M.S.H. and T.S.U.; visualization, Z.F.; supervision, A.R., S.M.S.H. and T.S.U.; funding acquisition, T.S.U. All authors have read and agreed to the published version of the manuscript.

Funding: This research received no external funding. 
Data Availability Statement: All the data generated in present work is already available in the reported manuscript or cited accordingly.

Conflicts of Interest: The authors declare no conflict of interest.

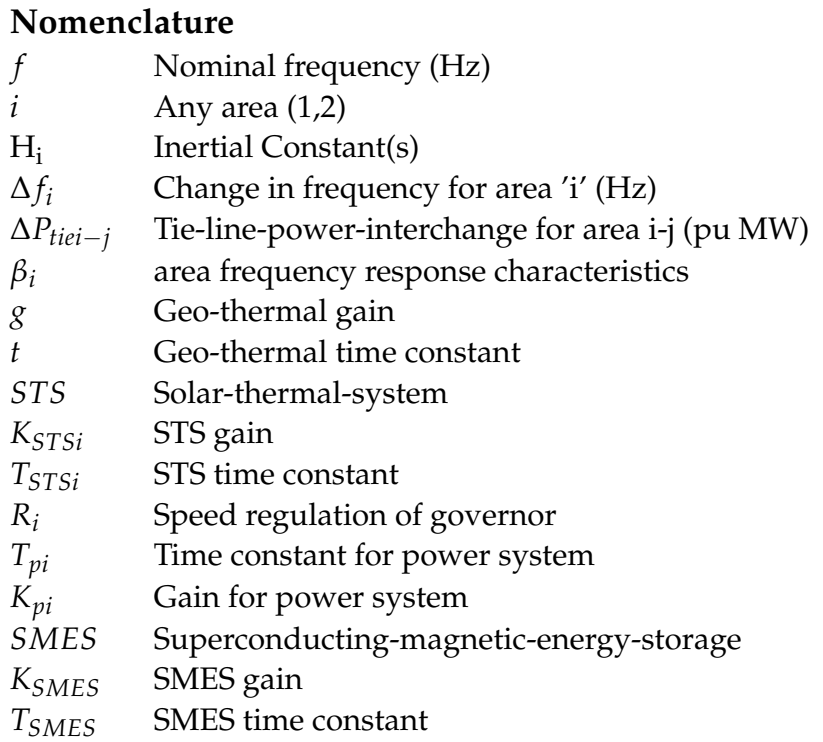

\section{Appendix A}

Nominal System Parameters

$\mathrm{f}=60 \mathrm{~Hz}$; Loading= 50\%; $K_{p i}=120 \mathrm{~Hz} /$ p.u. MW; $T_{\text {pi }}=20 \mathrm{~s} ; R_{\mathrm{i}}=2.4 \mathrm{~Hz} /$ p.u. MW;

$D_{\mathrm{i}}=8.33 \times 10^{-3}$ p.u. MW $/ \mathrm{Hz} ;$ Bias $_{\mathrm{i}}=\beta_{\mathrm{i}}=0.425$ p.u. $\mathrm{MW} / \mathrm{Hz} ; H_{\mathrm{i}}=5 \mathrm{~s} ; \mathrm{a} 12=-1 / 3$;

Conventional-Thermal: $T_{\mathrm{ti}}=0.3 \mathrm{~s}, T_{\mathrm{gi}}=0.08 \mathrm{~s}, T_{\mathrm{ri}}=10 \mathrm{~s}, K_{\mathrm{ri}}=0.5$;

Solar-Thermal: $K_{\mathrm{STS}}=1 ; T_{\mathrm{STS}}=1$;

Geo-Thermal: $g=0.1095, t=0.0731 \mathrm{~s}$

SMES: $K_{\text {SMES }}=0.12 ; T_{\text {SMES }}=0.03 \mathrm{~s}$;

\section{References}

1. Farooq, Z.; Rahman, A.; Ahmad Lone, S. Load frequency control of multi-source electrical power system integrated with solar-thermal and electric vehicle. Int. Trans. Electr. Energy Syst. 2021, 31, e12918. [CrossRef]

2. Safiullah, S.; Rahman, A.; Lone, S.A. State-observer based IDD controller for concurrent frequency-voltage control of a hybrid power system with electric vehicle uncertainties. Int. Trans. Electr. Energy Syst. 2021, 31, e13083. [CrossRef]

3. Latif, A.; Hussain, S.S.; Das, D.C.; Ustun, T.S.; Iqbal, A. A review on fractional order (FO) controllers' optimization for load frequency stabilization in power networks. Energy Rep. 2021, 7, 4009-4021. [CrossRef]

4. Christie, R.; Wollenberg, B.; Wangensteen, I. Transmission management in the deregulated environment. Proc. IEEE 2000, 88, 170-195. [CrossRef]

5. Sahu, R.K.; Panda, S.; Rout, U.K.; Sahoo, D.K. Teaching learning based optimization algorithm for automatic generation control of power system using 2-DOF PID controller. Int. J. Electr. Power Energy Syst. 2016, 77, 287-301. [CrossRef]

6. Subbaramaiah, k. Improvement of dynamic performance of SSSC and TCPS based hydrothermal system under deregulated scenario employing PSO based dual mode controller. Eur. J. Sci. Res. 2011, 57, 230-243.

7. Zare, K.; Hagh, M.T.; Morsali, J. Effective oscillation damping of an interconnected multi-source power system with automatic generation control and TCSC. Int. J. Electr. Power Energy Syst. 2015, 65, 220-230. [CrossRef]

8. Rahman, A.; Saikia, L.C.; Sinha, N. Automatic generation control of an unequal four-area thermal system using biogeographybased optimised 3DOF-PID controller. IET Gener. Transm. Distrib. 2016, 10, 4118-4129. [CrossRef]

9. Lee, D.J.; Wang, L. Small-Signal Stability Analysis of an Autonomous Hybrid Renewable Energy Power Generation/Energy Storage System Part I: Time-Domain Simulations. IEEE Trans. Energy Convers. 2008, 23, 311-320. [CrossRef]

10. Das, D.C.; Sinha, N.; Roy, A. Small signal stability analysis of dish-Stirling solar thermal based autonomous hybrid energy system. Int. J. Electr. Power Energy Syst. 2014, 63, 485-498. [CrossRef]

11. Farooq, Z.; Rahman, A.; Lone, S.A. System dynamics and control of EV incorporated deregulated power system using MBOoptimized cascaded ID-PD controller. Int. Trans. Electr. Energy Syst. 2021, 31, e13100. [CrossRef] 
12. Safiullah, S.; Rahman, A.; Ahmad Lone, S. Optimal control of electrical vehicle incorporated hybrid power system with second order fractional-active disturbance rejection controller. Optim. Control. Appl. Methods 2021. [CrossRef]

13. Rahman, A.; Saikia, L.C.; Sinha, N. Automatic generation control of an interconnected two-area hybrid thermal system considering dish-stirling solar thermal and wind turbine system. Renew. Energy 2017, 105, 41-54. [CrossRef]

14. Hossain, M.; Madlool, N.; Rahim, N.; Selvaraj, J.; Pandey, A.; Khan, A.F. Role of smart grid in renewable energy: An overview. Renew. Sustain. Energy Rev. 2016, 60, 1168-1184. [CrossRef]

15. Nadeem, F.; Hussain, S.M.S.; Tiwari, P.K.; Goswami, A.K.; Ustun, T.S. Comparative Review of Energy Storage Systems, Their Roles, and Impacts on Future Power Systems. IEEE Access 2019, 7, 4555-4585. [CrossRef]

16. Elsisi, M.; Soliman, M.; Aboelela, M.; Mansour, W. Improving the grid frequency by optimal design of model predictive control with energy storage devices. Optim. Control. Appl. Methods 2017, 39, 263-280. [CrossRef]

17. Lu, C.F.; Liu, C.C.; Wu, C.J. Effect of battery energy storage system on load frequency control considering governor deadband and generation rate constraint. IEEE Trans. Energy Convers. 1995, 10, 555-561.

18. Tasnin, W.; Saikia, L.C. Performance comparison of several energy storage devices in deregulated AGC of a multi-area system incorporating geothermal power plant. IET Renew. Power Gener. 2018, 12, 761-772. [CrossRef]

19. Pradhan, P.C.; Sahu, R.K.; Panda, S. Firefly algorithm optimized fuzzy PID controller for AGC of multi-area multi-source power systems with UPFC and SMES. Eng. Sci. Technol. Int. J. 2016, 19, 338-354. [CrossRef]

20. Heimisson, B. Improved frequency control strategies for geothermal power plants. Master's Thesis, Chalmers University of Technology, Gothenburg, Sweden, 2014.

21. Tasnin, W.; Saikia, L.C.; Rajbongshi, R.; Saha, D.; Saha, A. Effect of Geothermal and Other Renewables on AGC of an Interconnected Thermal System. In Innovations in Infrastructure; Deb, D., Balas, V., Dey, R., Eds.; Advances in Intelligent Systems and Computing; Springer: Berlin/Heidelberg, Germany, 2019; Volume 757. [CrossRef]

22. Pappachen, A.; Fathima, A.P. Critical research areas on load frequency control issues in a deregulated power system: A state-of-the-art-of-review. Renew. Sustain. Energy Rev. 2017, 72, 163-177. [CrossRef]

23. Parida, M.; Nanda, J. Automatic generation control of a hydro-thermal system in deregulated environment. In Proceedings of the 2005 International Conference on Electrical Machines and Systems, Beijing, China, 27-29 September 2005; Volume 2, pp. 942-947.

24. Rahman, A.; Saikia, L.C.; Sinha, N. Load frequency control of a hydro-thermal system under deregulated environment using biogeography-based optimised three-degree-of-freedom integral-derivative controller. IET Gener. Transm. Distrib. 2015, 9, 22842293. [CrossRef]

25. Kumar, J.; Ng, K.H.; Sheble, G. AGC simulator for price-based operation. I. A model. IEEE Trans. Power Syst. 1997, 12, 527-532. [CrossRef]

26. Donde, V.; Pai, M.; Hiskens, I. Simulation and optimization in an AGC system after deregulation. IEEE Trans. Power Syst. 2001, 16, 481-489. [CrossRef]

27. Debbarma, S.; Saikia, L.C.; Sinha, N. AGC of a multi-area thermal system under deregulated environment using a non-integer controller. Electr. Power Syst. Res. 2013, 95, 175-183. [CrossRef]

28. Bhatt, P.; Roy, R.; Ghoshal, S. Optimized multi area AGC simulation in restructured power systems. Int. J. Electr. Power Energy Syst. 2010, 32, 311-322. [CrossRef]

29. Daraz, A.; Malik, S.A.; Mokhlis, H.; Haq, I.U.; Zafar, F.; Mansor, N.N. Improved-Fitness Dependent Optimizer Based FOI-PD Controller for Automatic Generation Control of Multi-Source Interconnected Power System in Deregulated Environment. IEEE Access 2020, 8, 197757-197775. [CrossRef]

30. Ebrahim, M.A.; Becherif, M.; Abdelaziz, A.Y. PID-/FOPID-based frequency control of zero-carbon multi sources-based interconnected power systems under deregulated scenarios. Int. Trans. Electr. Energy Syst. 2021, 31, 1-22. [CrossRef]

31. Tasnin, W.; Saikia, L.C.; Raju, M. Deregulated AGC of multi-area system incorporating dish-Stirling solar thermal and geothermal power plants using fractional order cascade controller. Int. J. Electr. Power Energy Syst. 2018, 101, 60-74. [CrossRef]

32. Mohanty, B.; Hota, P.K. Comparative performance analysis of fruit fly optimisation algorithm for multi-area multi-source automatic generation control under deregulated environment. IET Gener. Transm. Distrib. 2015, 9, 1845-1855. [CrossRef]

33. Dash, P.; Saikia, L.C.; Sinha, N. Automatic generation control of multi area thermal system using Bat algorithm optimized PD-PID cascade controller. Int. J. Electr. Power Energy Syst. 2015, 68, 364-372. [CrossRef]

34. Veerasamy, V.; Wahab, N.I.A.; Ramachandran, R.; Othman, M.L.; Hizam, H.; Irudayaraj, A.X.R.; Guerrero, J.M.; Kumar, J.S. A Hankel Matrix Based Reduced Order Model for Stability Analysis of Hybrid Power System Using PSO-GSA Optimized Cascade PI-PD Controller for Automatic Load Frequency Control. IEEE Access 2020, 8, 71422-71446. [CrossRef]

35. Latif, A.; Hussain, S.S.; Das, D.C.; Ustun, T.S. State-of-the-art of controllers and soft computing techniques for regulated load frequency management of single/multi-area traditional and renewable energy based power systems. Appl. Energy 2020, 266, 114858. [CrossRef]

36. Moosavi, S.H.S.; Bardsiri, V.K. Satin bowerbird optimizer: A new optimization algorithm to optimize ANFIS for software development effort estimation. Eng. Appl. Artif. Intell. 2017, 60, 1-15. [CrossRef]

37. Johnson, M.A.; Moradi, M.H. PID Control: New Identification and Design Methods; Springer: Berlin/Heidelberg, Germany, 2005 [CrossRef] 